\title{
PROVIDÊNCIAS CABRALINAS
}

\author{
Homero José Vizeu Araújo
}

RESUMO: The cultural environment of the fifties and sixties and its effects on João Cabral's poetry. The conservative modernization of the country creates the beginnings of cultural industry, which allows a secondary role for literature, despite the importance of literature in the elite circles. Cabral's poetry is a sophisticated reaction to this situation.

PALAVRAS-CHAVE: João Cabral, poesia brasileira, Antonio Candido, Formação da Literatura Brasileira, década de 50 e 60, modernização, bossa nova, concretismo, indústria cultural.

O antilírico na periferia da periferia do capitalismo - Cabral se diz poeta pernambucano, não propriamente brasileiro - tem que tomar severas providências para garantir autoridade a sua voz. Para tal, há que se fazer um duro enfrentamento com a realidade nordestina e sua aridez e daí extrair lições que auxiliem no projeto de buscar o impossível de poema referido em Antiode. Assim, aridez pernambucana e pesquisa da realidade se casam sem atrito com a denúncia do poema e suas boas intenções, fazendo com que Cabral torne-se um poeta particularmente mal intencionado, no sentido da desconfiança pregada por Walter Benjamin e assumida numa escala quase inédita na Literatura Brasileira, com a exceção provável de Machado de Assis. Alguns dos traços malignos e escarninhos do narrador machadiano ${ }^{1}$ estão também no humor de Cabral, um admirador, assim como Machado, da ironia e do humor setecentista inglês. Consulte-se em A educação pela pedra, o poema The country of the Houyhnhnms.

A peculiaridade da dicção cabralina necessariamente passa pelo reaproveitamento de temas que despontam em momentos da poesia brasileira. A obsessão cabralina pela pedra, que será deflagrada nos anos 60 , ilumina a distância entre Cabral e seus contemporâneos, para não mencionar a tradição que remonta no mínimo a Cláudio Manuel da Costa. Em Geometria da Composição, Ivo Barbieri invoca exemplos ilustres, indo das penhas de Cláudio, passando por $O$ Gigante de

Homero José Vizeu Araújo é professor de Literatura Brasileira da UFRGS.

${ }^{1}$ Ver SCHWARZ, Roberto. “1. Observações iniciais” e "2. Um princípio formal”, 1990. 
Pedra de Gonçalves Dias, versos de As metamorfoses de Murilo Mendes e, claro, chegando à pedra no meio do caminho de Drummond.

Barbieri nota que já em Cláudio Manuel da Costa as pedras são elementos típicos da paisagem nativa do poeta, segundo o comentário já clássico de Antonio Candido, em Formação da Literatura Brasileira. Em Gonçalves Dias o esforço de caracterização da natureza nacional vem acompanhado de grandiloqüência que dignifica a solidez e a resistência do fenômeno geológico, que não estaria sujeito às vicissitudes do tempo ${ }^{2}$. O excesso verbal de Gonçalves Dias revelaria, por contraste, a eficácia da contenção de Cabral.

A recorrência da pedra na obra de Drummond, por sua vez, assinalaria momentos cruciais na trajetória do poeta: de No meio do caminho, de Alguma Poesia, 1930, passando por Legado, em Claro Enigma, 1951, e por Lição de Coisas, 1962. Em Drummond a pedra registra, mais ou menos, o não-dito, algo que não se pode, a rigor, nomear, enquanto em Cabral a pedra tende à saturação e à concretude do explícito.

"A imaginação da pedra, que atravessa três séculos de poesia no Brasil, assume nele a função de imagem modeladora de uma nova concepção poética e de uma ascética concepção da vida. Imagem do concreto por excelência, a pedra ensina a linguagem da dureza, e do dizer compacto, tenacidade daquele que, impermeável à diluição da fluência e à anulação na passividade, permanece sempre incisivo e ativo" (Ibidem, p.93).

Incisividade e estado de alerta que se condensam na pedra, mas que tem um ilustre antecedente na idéia fixa da faca só lâmina, que talvez tenha sido um patamar necessário para que Cabral se voltasse para a imaginação da pedra da tradição brasileira. Para requalificar a imagem da pedra e alcançar uma provocação e um alerta ao leitor que não deixa de ser uma crítica ao próprio sistema literário, Cabral faz um percurso que é nosso assunto neste trabalho e que inclui uma definição das exigências a serem feitas ao leitor.

A ironia do antilírico estabelece o dispositivo poético que denuncia e aciona o leitor ao mesmo tempo. Já notamos que não parece ser por acaso que a suprema exigência feita ao público é contemporânea do poema que mais concessões faz ao público: o auto de natal Morte e vida severina, encantatório, harmonioso e marcado pela compaixão. A disposição democrática que põe em cena o nordestino destituído e explorado corresponde a um período em que opções artísticas estão inseridas num clima de polêmica política. Assim é que os esforços de João Cabral coincidem, em larga medida, com a redemocratização depois do Estado Novo, as promessas do desenvolvimentismo e os debates conexos, ambiente que abriga e alimenta aquela já citada consciência catastrófica do atraso, diagnosticada por Antonio Candido. Um período de debates, cuja história e avaliação ainda está por ser feita, que acompanha o período democrático iniciado com o fim da ditadura Vargas, em 45, e encerra-se com o golpe de 64, deflagrador da ditadura mais recente.

${ }^{2}$ Cf. BARBIERI, 1997, p. 92. 
O auto de natal pernambucano foi escrito por encomenda de Maria Clara Machado, do grupo Tablado, que jamais encenou a peça; Morte e vida severina só chegaria aos palcos na década de 60 com música de Chico Buarque de Holanda, alcançando sucesso que também ecoa a politização ambiente e específica do mundo teatral. Em oposição ao convencionalismo de TBC, Teatro Brasileiro de Comédia, haviam surgido o Arena e o Oficina. O dramaturgo e ator Gianfrancesco Guarnieri condenava os valores "burgueses" do TBC, demandava um teatro popular capaz de atingir as massas, mas reconhecia ser inalcançável a meta no contexto em que se vivia. Augusto Boal, dramaturgo e teórico de esquerda, chegará a distinguir três fases na história do teatro nacional: o teatro alienado, o autêntico e o popular. ${ }^{3} \mathrm{O}$ TBC era a súmula da alienação a agradar a platéia burguesa e a recusar-se a discutir as questões nacionais; o Arena discute e politiza mas se limita ao público de "classe média", é autêntico. É o teatro autêntico que deveria encontrar o caminho das massas mediante um novo meio de expressão e divulgação. Em mais de um sentido, tal missão será assumida pelo CPC da UNE.

Renato Ortiz, ao referir o debate, trata de notar que a questão do público é central (1994, p.103); dependendo da proposta, a platéia deve responder aos apelos da ostentação burguesa, do nacionalismo radical de classe média ou das propostas revolucionárias de interesse popular. Se a platéia popular e radicalizada não comparece, o público bem pensante e inserido no debate trata de garantir a recepção das mensagens antiimperialistas, socialistas, etc. O golpe de 1964, diga-se, não interrompeu o debate. Tendo se voltado basicamente para a intervenção em sindicatos, repressão na zona rural, dissolução de partidos políticos e de organizações estudantis, etc., poupou a "presença cultural da esquerda".

"Apesar da ditadura da direita há relativa hegemonia cultural da esquerda no país. Pode ser vista nas livrarias de São Paulo e Rio, cheias de marxismo, nas estréias teatrais, incrivelmente festivas e febris, às vezes ameaçadas de invasão policial, na movimentação estudantil ou nas proclamações do clero avançado. Em suma, nos santuários da cultura burguesa a esquerda dá o tom. Esta anomalia - que agora periclita, quando a ditadura decretou penas pesadíssimas para a propaganda do socialismo - é o traço mais visível do panorama cultural brasileiro entre 64 e 69" (SCHWARZ, 1992, p.62).

Uma hegemonia de âmbito assaz restrito, o que em parte determina a estridência e exasperação das manifestações: trata-se de

"grupos diretamente ligados à produção ideológica, tais como estudantes, artistas, jornalistas, parte dos sociólogos e economistas, a parte raciocinante do clero, arquitetos, etc. - mas daí não sai, nem pode sair, por razões policiais. Os intelectuais são de esquerda, e as matérias que preparam de um lado para as comissões do governo ou do grande capital, e do outro para as rádios, televisões e os jornais do país, não são. É de esquerda somente a matéria que o grupo - numeroso a ponto de formar um bom

${ }^{3}$ Os argumentos de um e de outro encontram-se em GUARNIERI, 1981 e BOAL, 1981. 
mercado - produz para consumo próprio. Esta situação cristalizou-se em 64, quando grosso modo a intelectualidade socialista, já pronta para prisão, desemprego e exílio, foi poupada" (Ibidem, p.62).

Este o destino melancólico do debate alimentado pelo período democrático, comprimido agora pelas forças militares e conservadoras que tomaram a si a tarefa de mais um salto na modernização recuperadora de periferia. Restrito e acuado, trata-se de mais um "autopúblico", no batismo certeiro de Antonio Candido ao analisar os impasses da vida intelectual colonial e sua organização em academias e grêmios ${ }^{4}$ de escassa ressonância social. Ao repetir o isolamento da vida bem-pensante duzentos anos depois, é de se argumentar que alguma farsa era inevitável, mesmo que entremeada do heroísmo de quem enfrentava a brutalidade descomunal da direita paramilitar ou oficial. Por acaso nenhum, os grupos "raciocinantes" são as vítimas preferidas de Nelson Rodrigues, que nas suas estupendas crônicas e no calor da hora tratou de imortalizá-los satiricamente no Padre de passeata, na Estagiária de Jornalismo de calcanhar sujo, na Grã-Fina de narinas de cadáver, etc..$^{5}$ Uma síntese estética que explode na grande imprensa do país e inclui autonomia intelectual, deboche carioca, retórica maledicente e um ouvido afinadíssimo para a língua falada, do qual o autor, é claro, já dera notícia no sua consagrada obra teatral.

Se este é o desfecho do processo, entre melancólico, cômico e grotesco sob a ditadura militar, é bom não perder de vista que a redemocratização do país pós-45 detonara um esforço na área cultural que, em São Paulo, renderam a fundação do Museu de Arte de São Paulo (1947), do Museu de Arte Moderna (1948), do já citado Teatro Brasileiro de Comédia (1948) e da Bienal. Um conjunto de realizações notáveis que inclui a criação da companhia cinematográfica Vera $\mathrm{Cruz}^{6}$, na qual a burguesia paulista, suficientemente endinheirada para gastos suntuários de monta, busca afirmação e legitimação no domínio da cultura. Até certo ponto trata-se de tentar cinema "sério" de padrão hollywoodiano contra a chanchada carioca, que era cinema popular, humorístico e paródico ${ }^{7}$, o que pode ser interpretado como mais um lance da força econômica paulista contra a hegemonia cultural da ainda capital política e administrativa do Brasil.

No quadro da música popular há uma área que reivindica maior rigor e inovação, o que deflagra a bossa nova, a valorizar o long-play para além dos singles

4"Vista do ângulo do consumo, não da produção literária, a agremiação desempenhou outra função de igual relevo: proporcionar a formação de um público para as produções literárias. Não apenas os próprios consócios formavam grupo receptor em relação uns aos outros, como as atividades gremiais reuniam ou atingiam os demais elementos que na Colônia estavam em condições de apreciá-las. Foi, portanto, um auto público, num país sem públicos.” (CANDIDO, 1981, p.79).

${ }^{5}$ A obra cronística de Nelson Rodrigues foi reeditada; para examinar a visão de Nelson sobre a tragicomédia ideológica da década de 60, vejam-se $O$ óbvio ululante, 1993 e A cabra vadia, 1995. Para uma avaliação bem-humorada e informadíssima do autor e de sua obra, consultar Inteligência com dor Nelson Rodrigues ensaista, de Luís Augusto Fischer, tese de doutorado apresentada ao Programa de Pós-Graduação em Letras da UFRGS, maio de 1998.

${ }^{6} \mathrm{Cf}$. CANDIDO, 1980.

${ }^{7}$ Para uma análise do fenômeno, ver AUGUSTO, 1989. 
ocasionais, a incluir a influência do jazz na batida do samba - uma síntese alcançada por João Gilberto, um intérprete que recompõe o que canta e toca - e a caprichar até na apresentação gráfica das capas dos discos. Inovações que mais do que atender às demandas da elite urbana informada e cosmopolita, respondem ao debate sobre as possibilidades de modernização da sociedade. Daí a racionalização e economia que retira até os artigos dos títulos dos lps: 'Samba Nova Canção", "Novas Estruturas", "Esquema 64", etc., cujo caráter conciso ecoa a linguagem das agências de publicidade. E Júlio Medaglia nota que há nomes que expõe o desejo de renovação e vanguardismo: "Avanço", "Revolução", "Impacto" (MEDAGLIA, 1978, p.98).

O livro Balanço da Bossa e outras Bossas, de Augusto de Campos contém, de resto, um conjunto muito valioso de informações a apontar aproximações possíveis entre a vanguarda musical erudita e alguns resultados da Bossa Nova, com ênfase nos procedimentos de reelaboração virtuosística de João Gilberto ${ }^{8}$. O conjunto de ensaios e comentários revela a disposição crítica e combativa de Augusto de Campos, que generosamente saúda a Bossa Nova e o Tropicalismo, mas não se priva de comentar a Jovem Guarda e o conjunto da música popular brasileira.

Devidamente provocado por Brasil Rocha Brito, o crítico e poeta concreto trata de associar as letras da Bossa Nova a um "processo" que também incluiria o Concretismo:

"É verdade que se pode detectar, na tradição da música popular, exemplos de um isomorfismo de $1^{\circ}$ grau, imitativo ou fisionômico (Gago apaixonado, de Noel Rosa). No caso da Bossa Nova, porém, o processo se reveste de outras implicações, caracterizando-se por uma intencionalidade crítica mais definida, que supera as utilizações episódicas ou meramente caricaturais. Assim, algumas letras da Bossa Nova configuram uma tendência que, de certa forma, numa faixa de atuação própria - a da canção popular - corresponde às manifestações da vanguarda poética, participando com ela de um mesmo processo cultural" (BRITO, In CAMPOS, p.39).

As restrições de Augusto de Campos (de certa forma, numa faixa de atuação própria) são sintomáticas em autor tão enfático e disposto ao combate: afinal a Bossa Nova tende a valorizar a coloquialidade, a sintaxe da fala e a escassa ênfase em uma "faixa de atuação" lírica e emotiva muito distante dos experimentos concretistas. Fato que não cancela o ânimo inovador a aproximar uns e outros, de cujas afinidades eletivas o livro organizado por Augusto de Campos dá testemunho relevante.

Ao associar à batida do samba o jazz e as harmonias sofisticadas que ecoam experiências eruditas, em parte filtradas já pelo cancioneiro norte-americano, a Bossa Nova incorpora novas informações à música popular brasileira, a ponto de ser acusada, pelos tradicionalistas, de desfigurar nosso patrimônio. De fato, as reinterpretações de João Gilberto não podem deixar de soar sacrílegas aos ouvidos de um crítico como José Ramos Tinhorão, inclusive porque respondem por uma nova inserção da inspiração nacional no mercado internacional. Júlio Medaglia, um conhecedor do assunto, avalia que finalmente chegou-se àquele ponto almejado por Oswald de Andrade, de

${ }^{8} \mathrm{Cf}$. Balanço da Bossa e outras bossas. 
uma arte de exportação brasileira, em termos a que não falta certo ufanismo ingênuo. "A BN, forma de expressão musical que se popularizou em meio a grandes polêmicas, adquiriu muito rapidamente sua estabilidade e maturidade de propósitos, com base numa militância anônima inicial, até a grande produção e consumo da fase profissional posterior, quando se transformou num produto brasileiro de exportação dos mais refinados e requisitados no exterior" (MEDAGLIA, In CAMPOS, p.70).

$\mathrm{O}$ acesso ao mercado internacional mediante "grande produção e consumo da fase profissional", posterior a um período relativamente artesanal, tem um quê de abrupto a ressoar os "cinqüenta anos em cinco" do período juscelinista, um salto qualitativo que é incorporado naturalmente ao otimismo que acompanha o debate das possibilidades do país. Inserida no ambiente repleto de promessas, a receita cabralina de poesia prosaica tributária da tradição espanhola e nordestina é de um curioso arcaísmo, como se o poeta desse um passo atrás e tratasse de pôr as barbas de molho, em contraste altamente revelador com a posição assumida pelo concretismo, para mencionar um movimento que incluiu Cabral entre seus antecessores:

"precursores: mallarmé (un coup de dés, 1897): o primeiro salto qualitativo: "subdivisions prismatiques de l'idée"; espaço ("blancs") e recursos tipográficos como elementos substantivos da composição. pound (the cantos): método ideogrâmico. joyce (ulysses e finnegans wake): palavraideograma; interpenetração orgânica de tempo e espaço. (...) no brasil: oswald de andrade (1890-1954): "em comprimidos, minutos de poesia". joão cabral de melo neto (n. 1920) - o engenheiro e a psicologia da composição mais antiode): linguagem direta, economia e arquitetura funcional do verso." (Publicado originalmente em Noigandres 4, 1958, São Paulo, assinado por Augusto de Campos, Haroldo de Campos e Décio Pignatari) (In TELLES, p.403-4).

Apostando várias fichas nas possibilidades desalienantes da destruição da sintaxe e da reorganização da palavra, explorada em sua concretude física e "verbivocovisual", os concretos aderem à proposta oswaldiana de chegar a uma poesia de exportação, em dia com a pesquisa de ponta e atenta aos experimentos de última geração. É muito natural que tal vanguarda dê por encerrado "o ciclo histórico do verso". Mas o que isso tem a ver com cerrada armação sintática, em verso, de Cabral? João Cabral investe no pólo crítico, que denuncia e se autodenuncia; enquanto os concretos estão com a disposição pragmática que adere e celebra a cena contemporânea e a eles mesmos. Em Cabral a desconfiança, de si e dos outros, com os concretos a confiança e a autoconfiança dos portadores da boa nova.

Se cabe a João Cabral fazer a crítica de sua própria obra, de suas próprias pretensões de autor, se a ele cabe pôr em questão o sistema literário, não se espera de Cabral que pretenda munir o Brasil de uma poesia de exportação digna de constar entre as várias benesses do mundo moderno, tais como a indústria automobilística e a agitada vida urbana. A João Cabral cabe antes perguntar de que serve a poesia em uma sociedade assim estabelecida.

A concretude física e verbivocovisual rompe com a sintaxe e com o que seria 
expectativa amestrada e automatizada do sujeito urbano. A suprema vanguarda transgressora trata, portanto, de fornecer à literatura uma dimensão cosmopolita e $u p$ to date, literatura empenhada em munir o Brasil de atributos modernos cabíveis, mas não necessariamente disposta ao esforço crítico de examinar quais os limites de seu público e de sua própria linguagem. Neste sentido a vanguarda concretista toma para si a missão de contribuir para a glória do sistema, em mais uma tentativa de prover de uma benfeitoria moderna o país que se renova.

O movimento que se pretende herdeiro da ruptura modernista, acaba incumbido de missão análoga a dos árcades e românticos, só que em um contexto histórico um tanto adverso, pois a ruptura agora já é a regra ditada pelo mercado e pelo publicidade agressiva. A literatura, por sua vez, longe de ser o centro da vida cultural é só mais um dado, não necessariamente relevante, no âmbito da indústria cultural. Mais pitoresco ainda é que tal vanguarda lança mão da função poética jakobsoniana para defender a utilização de meios sofisticados de expressão que apontam para a autonomia da arte, ao mesmo tempo que defende o caráter utilitário de uma arte que atenda as demandas do sujeito urbano de sensibilidade transformada. No comentário agudo de Iumna Maria Simon sobre a depuração formal dos poemas concretos da fase heróica:

"Como organização interna, os poemas mantém um refinamento formal e estético de certo modo estranho à idéia de arte popular, pronta para sair pelas ruas da cidade e ser compreendida pelos transeuntes assoberbados e distraídos. Os dispositivos modernizadores põem em funcionamento microestruturas formais (as chamadas estruturas "verbivocovisuais") que nada mais são do que a plenitude material dos eternos mecanismos poéticos. O poema concreto apresenta uma sistematização plástica dos procedimentos que se encontram dispersos e rarefeitos no poema em verso de todos os tempos (rima, paronomásia, assonância, aliteração, anáfora, elipse, assíndeto, entre outros tantos). (...) Aquele mesmo trabalho que está, digamos, em Homero, Dante, Camões e na poesia concreta, só que esta paradoxalmente é a que mais o valoriza na medida em que dispensa tudo aquilo que não sejam evidências materiais do esplendor da função poética da linguagem." (SIMON, 1990, p.126-7).

"Como entender o fundamento de um plano de composição antiliterário que todavia se respalda no mais literário, no puro poético?" (Ibidem, p.127). Um impasse que reúne o supremo esteticismo à participação entendida como consumo da poesia, a qual viria a se integrar ao cotidiano do público. Qual público? Qual sociedade? A sociedade brasileira sob modernização heterogênea, desigual e combinada é assunto a ser analisado ou criticado por tal poesia? No esforço de adesão ao desenvolvimentismo e de estabelecimento de uma poesia de ponta, a crítica à possibilidade da poesia e a dúvida sobre o papel da poesia na situação brasileira - questões recorrentes em Cabral - não comparecem.

"Tal paradoxo vale para os futuros desdobramentos desta vanguarda, os quais representarão esforços teóricos diferentes no sentido de incorporar ao projeto e à prática criativa as mudanças políticas, sociais e culturais 
ocorridas no Brasil e no mundo nas três décadas que virão. Assim é que nos anos 60 a poesia concreta se propôs a ser participante, pop, semiótica, do mesmo modo que mais recentemente se deu ao luxo de se proclamar pós-utópica (pós-modernismo envergonhado?), contanto que sua linguagem fique preservada como um ideal absoluto e aistórico de modernidade." (Ibidem, p.127).

Digamos que seja o preço a ser pago por quem se dispõe a dotar o Brasil da poesia que ele merece, do ponto de vista construtivo e um tanto provinciano de quem pretende ter acesso à modernidade, por mais que a modernização social do país não alcance os ideais civilizatórios desejáveis. O paradoxo do esteticismo participante acaba saudado como solução pelos concretos e não tomado como problema, enquanto Cabral, mediante um verso que se aproxima da prosa, trata do problema e critica, repita-se, o próprio sistema literário, o que, no contexto, equivale a recusar-se a contribuir para mais um esforço autocongratulatório de celebrar a contribuição do Brasil ao concerto das nações.

Na década de 70, em Museu de tudo, é de se registrar a disposição desencantada e agressiva com relação ao leitor, não obstante o estoicismo irônico da autoreferência:

\section{O ARTISTA INCONFESSÁVEL}

"Fazer o que seja é inútil.

Não fazer nada é inútil.

Mas entre fazer e não fazer

mais vale o inútil do fazer.

Mas não, fazer para esquecer

que é inútil: nunca o esquecer.

Mas fazer o inútil sabendo

que ele é inútil, e bem sabendo

que é inútil e que seu sentido

não será sequer pressentido,

fazer: porque ele é mais difícil

do que não fazer, e difícil-

mente se poderá dizer

com mais desdém, ou então dizer

mais direto ao leitor Ninguém

que o feito o foi para ninguém."

A dificuldade do fazer é enunciada e exibida na elaboração do poema, com suas rimas aos pares entre palavras idênticas, sem que a repetição dos termos impeça o desenvolvimento da argumentação implacável. Enunciado e elaboração são uma demonstração de perícia, do fazer difícil, que é aconselhado/ argumentado no infinitivo sem que o poeta determine quem dá ou recebe o conselho/argumento. Não há um sujeito, um eu-lírico a expor abertamente suas intenções, embora seja argumentável que enunciado e elaboração tratam de evidenciar, com um toque de malícia, o narcisismo da persona poética de Cabral, a qual de novo reincide no seco, agressivo 
e anti-eu/ antilírico do conjunto da obra como que a reivindicar, em tour de force, o lugar comum da crítica nem sempre benévola.

Para Marta Peixoto, e no interior de Museu de Tudo que contém vários poemas voltados para a produção artística alheia, a autocrítica chega a lembrar os impasses de Fábula de Anfion.

"O artista inconfessável, que não pode ou não deve confessar-se, no entanto confessa dúvidas que atingem fundo à prática cabralina de dar valor incontestável ao fazer como maneira de assegurar a comunicação. Mesmo o construir fechado de $A$ Educação pela Pedra se justifica por impor obstáculos que incentivam a leitura atenta. Em "O artista inconfessável", em circuito problemático que faz lembrar a "Fábula de Anfion", dissipa-se tanto o otimismo construtor quando a crença numa provável comunicação com o leitor." (PEIXOTO, 1983, p.204).

De fato, algumas "crenças" cabralinas são denunciadas pelo poema, que no entanto exige uma leitura menos linear e mais desconfiada do que a proposta por Marta Peixoto. O caráter inconfessável do artista também parece ser uma espécie de zombaria com os feitos alcançados e com a alegada recusa do confessional, inconfessável plenamente "confessado" ou figurado no infinitivo verbal que se repete de alto a baixo no poema. A reincidência no inútil do que é feito é falsamente redundante e acentua o procedimento necessário de quem, desde muito insiste em Vinte palavras sempre as mesmas/ de que conhece o funcionamento,/ a evaporação, a densidade/ menor que a do ar.

Agora a perícia está serviço do comentário auto-irônico e da recusa do leitor, que não é exortado mediante a função conativa, mas referido com todas as letras. $\mathrm{O}$ desdém configura o desprezo um tanto aristocrático de quem domina sua arte para além da compreensão dos tapados que não captam o sentido (e que seu sentido/não será sequer pressentido) de sua arte.

A ausência da função conativa ocorre quando leitor é nomeado e recusado, portanto é razoável crer que equivale a uma disposição negativista a expelir o leitor daquele dispositivo tão arduamente pesquisado na obra cabralina até Uma faca só lâmina, mas não só até ali. Um sinal de que, em alguma medida, cancelou-se a pretensão construtiva que fazia parte da agressão de João Cabral. Por outro lado, só o leitor ingênuo aceitaria o desprezo "confessado" pelo poeta sem retrucar que quem desdenha também deseja ser lido. Do contrário, para que publicar? Sendo assim, o dispositivo expulsa e inclui, morde e assopra, em alternância desconcertante para quem lê, que parece denunciar certa exasperação de quem escreveu.

De volta aos anos 50, nota-se que João Cabral recusa-se à adesão aos planos otimistas dos contemporâneos voltados para o futuro, mas também não se dispõe a lançar o olhar desencantado para o passado, na perspectiva dos fazendeiros do ar Drummond, Quintana, Bandeira, etc.; sem memória e sem edificação progressista, para Cabral restam a ironia e o distanciamento e talvez a justificativa da provocação. O dispositivo poético montado estabelece a posição do poeta no próprio sistema literário e no debate cultural, que se nutre das possibilidades democráticas inclusive para a crítica radical, como se vê na discussão sobre o público do teatro e de arte em 
geral. Em João Cabral, o dispositivo poético responde também a este debate e permite uma reavaliação da poesia brasileira ao associar-se à economia e contenção da poesia espanhola e aos efeitos ásperos da poesia popular nordestina para garantir um ritmo prosaico no verso que se quer rítmico mas sem a melodia do lirismo português.

Uma disposição crítica do poeta análoga, como já foi dito na introdução, à consciência catastrófica do atraso que, além de render certa urgência meio cômica no debate (bossa nova versus samba autêntico, TBC burguês versus voluntarismo radical do Arena, Vera Cruz versus Atlântida versus Cinema Novo, etc), também alimenta o surto mais recente e muito informado e elaborado das Formações: Formação Econômica do Brasil, de Celso Furtado, de 1959, Os donos do poder - Formação do patronato político brasileiro, de Raymundo Faoro, de 1958, e Formação da Literatura Brasileira, de Antonio Candido, de 1959. Nesta última, expõe-se com notável acuidade crítica a perspectiva materialista de que a literatura enquanto sistema é um circuito que inclui autor, obra e público, noção que corresponde aos termos da pesquisa cabralina na caça à sua definição de poesia, que de resto pode ser incluída na tendência à Nova Austeridade surgida depois da Segunda Guerra, segundo Michael Hamburger.

Em João Cabral encontra-se, assim, uma austeridade que lhe permite fazer o novo na poesia brasileira reelaborando a tendência cosmopolita a partir de um debate que amadurecia no país. Daí a possibilidade de expor o ponto fraco do sistema literário, o escasso público, que nem por isso será poupado de exigências, público que é parte da literatura segundo o ponto de vista da Formação, cuja publicação é posterior, no entanto, à pesquisa cabralina. Antonio Candido e João Cabral pesquisam paralelamente o mesmo problema, até por partilharem a "consciência catastrófica do atraso", que pode pôr em contraste vigor da tradição literária e descalabro social e daí, no ambiente de discussão ensejado pela redemocratização pós-Estado Novo, estabelecerem um ponto de vista de avaliação exigente.

Lançando o olhar ainda mais longe, se a harmonia bossanovista do final dos anos 50 era garantida pelas promessas modernizantes e fazia um fundo musical que ecoava o processo de maneira amena e contínua, cabia a Cabral a antimelodia da prosa; o que não significa que o poeta não tivesse ritmo, muito pelo contrário. E é defensável aproximar a anti-ênfase e economia de João Cabral da dicção e dissonâncias da Bossa Nova, embora seja inconcebível qualquer contato do confessionalismo às vezes piegas e patético do amor, da flor e do barquinho com o dispositivo poético armado pelo poeta.

De fato a beleza das dissonâncias e as promessas das letras da bossa-nova estão em dia com as exigências de um público de classe média urbana cada vez mais informado, em geral, e interessado em jazz, em particular; público implicado naquela modernização prometida por Juscelino. Mas a aspereza de João Cabral é mais aparentada com a Bossa Nova de "protesto", já da década de 60, como registrou Augusto de Campos no livro já citado 9 . É um sinal dos tempos que as amenidades iniciais da

9 “Também o clima 'intimista' ou 'participante' não influi decisivamente no estilo. Nara Leão, Carlos Lira, Edu Lobo ou Chico Buarque (como intérpretes), e mesmo o Geraldo Vandré de Canção Nordestina, não fogem a uma fundamental enxutez interpretativa, característica da BN. E a própria música popular 
bossa nova tenham derivado, entre outros resultados, para a contestação do regime e para a denúncia do imperialismo e do latifúndio.

É só então que Morte e vida severina, pronto desde meados dos anos 50, virá a ser encenado e a alcançar justo sucesso nos anos sessenta, isto é, no quadro de acirramento dos antagonismos despertados pela inserção, em marcha forçada, do Brasil no âmbito capitalista de padronização e de consumo, isto é, quando se deflagra a crise do populismo e ressurge o autoritarismo em escala nacional. $\mathrm{O}$ adeus às ilusões do desenvolvimento econômico autônomo vem acompanhado, no plano cultural, do ritmo cepecista adequado ao sucesso de Morte e vida severina.

A denúncia das barbaridades de um Brasil distante dos efeitos benéficos da modernização que alteram o complexo urbano desde 30, a denúncia do latifúndio, em suma, é um dos eixos da crítica ao estado de coisas antes e depois de 1964, e nada mais adequado que o auto de João Cabral seja tão bem recebido em tal contexto. Pelo menos até que as trevas da AI-5 desçam sobre o país em 1968, quando qualquer exercício mais ou menos público de vida inteligente tornou-se suspeito perante as autoridades. Que o sucesso de Morte e vida severina perpetue o equívoco, de resto por inúmeros críticos denunciado, de que João Cabral é grande poeta quando registra mazelas nordestinas, mas que se torna cerebral e hermético em outros momentos da obra, é outro problema. Em parte tal problema foi rastreado aqui e o que se batizou de dispositivo poético cabralino é uma poderosa fórmula que permite ao poeta escrever poesia exigente e sofisticada sem abrir mão de certos compromissos com o público e com a sociedade.

Desconfiança, desconfiança e mais desconfiança. Trata-se de um investimento maciço no esforço crítico, uma pesquisa aturada e obsessiva que vem a deflagrar o dispositivo poético que atenda às exigências do poeta, desperte o leitor e esteja à altura dos desafios que as circunstâncias históricas apresentam, do que resulta a inclusão peculiar, autolimitada e ativa, do poema cabralino no sistema literário.

\section{BIBLIOGRAFIA}

AUGUSTO, Sérgio, Este mundo é um pandeiro: a chanchada de Getúlio a JK. São Paulo, Cinemateca Brasileira/Cia das Letras, 1989.

BARBIERI, Ivo. Geometria da composição - Morte e vida da palavra severina. Rio de Janeiro, Sette Letras, 1997.

BOAL, Augusto. Tentativa de análise do desenvolvimento do teatro brasileiro. In Arte em Revista, n.6, 1981.

nordestina, cuja influência se tem feito sentir mais recentemente nos caminhos da $\mathrm{BN}$, não está alheia a essa problemática. Berimbau x violino, carcará x rouxinol, a dura aspereza do Nordeste encontra a doce secura da bossa citadina e com ela se harmoniza naturalmente. Do 'lobo bobo' ao 'carcará' a música nova parece ter uma constante da qual não pode e não deve fugir, sob pena de perder muito de sua força e agressividade. Essa constante poderia ser definida com palavras de João Cabral de Melo Neto, em seu poema 'A Palo Seco'. Como diz Cabral, 'se diz a palo seco/ o cante sem guitarra;/ o cante sem; o cante; o cante sem mais nada'." "Da jovem guarda a João Gilberto". In CAMPOS, Augusto de. Op. cit. p.57. 
BRITO, Brasil Rocha. Bossa Nova. In CAMPOS, Augusto. Balanço da Bossa e outras bossas. 4 ed. São Paulo, Perspectiva, 1986.

CAMPOS, Augusto de. “João Gilberto/Anton Webern”. In CAMPOS, Augusto (org.) Balanço da Bossa e outras bossas. . CAMPOS, Haroldo de; PIGNATARI, Décio. "Plano-piloto para poesia concreta". In TELLES, Gilberto Mendonça. Vanguarda européia e modernismo brasileiro. 13ed. Petrópolis, Vozes, 1997.

CANDIDO, Antonio. "Feitos da Burguesia" In Teresina, etc. Rio de janeiro, Paz e Terra, 1980. . Formação da literatura brasileira. Belo Horizonte, Itatiaia, 1981.

FISCHER, Luís Augusto. Inteligência com dor-Nelson Rodrigues ensaísta. Tese de doutorado apresentada ao Programa de Pós-Graduação em Letras da UFRGS, maio de 1998.

GUARNIERI, Gianfrancesco. O teatro como expressão da realidade nacional. In Arte em Revista, n.6, 1981.

MEDAGLIA, Júlio. "Balanço da Bossa-Nova". In CAMPOS, Augusto (org.). Balanço da Bossa e outras bossas. São Paulo, Perspectiva, 1978.

ORTIZ, Renato. A moderna tradição brasileira. 5.ed. São Paulo, Brasiliense, 1994.

PEIXOTO, Marta. Poesia com coisas. São Paulo, Perspectiva, 1983. Debates.

RODRIGUES, Nelson. O óbvio ululante. São Paulo, Cia das Letras, 1993. A cabra vadia. São Paulo, Cia das Letras, 1995.

SCHWARZ, Roberto. Observações iniciais e Um princípio formal. In: Um mestre na periferia do capitalismo - Machado de Assis. São Paulo, Duas Cidades, 1990.

. Cultura e política, 1964-1969. In: O pai de família e outros estudos. 2.ed. São Paulo, Paz e Terra, 1992.

SIMON, Iumna Maria. "Esteticismo e participação: as vanguardas poéticas no contexto brasileiro (1954-1969)". Novos Estudos. São Paulo, Cebrap, n.26, p.126-7, mar. 1990 . 